\title{
O výskyte a hniezdení húsky štíhlej (Alopochen aegyptiaca) na Slovensku
}

\author{
On occurrence and breeding of the Egyptian Goose \\ (Alopochen aegyptiaca) in Slovakia
}

\section{Samuel PaČenovskí ${ }^{1}$ \& Andrea Lešoví ${ }^{2,3}$}

\author{
${ }^{1}$ Štátna ochrana prírody Slovenskej republiky, Správa Chránenej krajinnej oblasti Ponitrie a Chránenej \\ krajinnej oblasti Dunajské luhy, pracovisko Bratislava, Karloveská 63, 84104 Bratislava, Slovensko; \\ e-mail: samuel.pacenovsky@sopsr.sk \\ ${ }^{2}$ Štátna ochrana prírody Slovenskej republiky, Tajovského 28B, 97401 Banská Bystrica, Slovensko \\ ${ }^{3}$ Technická univerzita vo Zvolene, T. G. Masaryka 24, 96001 Zvolen, Slovensko
}

\begin{abstract}
Since the first occurrence of the Egyptian Goose (Alopochen aegyptiaca) in Slovakia in 1993, a significant increase in its abundance has been recorded, until end of 2019 as many as 103 observation records were found, from year 2007 several new records appear almost annually. The first breeding was confirmed in 2014, next two cases in 2015 and 2017. In 2019, the fourth breeding was documented in the city of Bratislava-at the Kuchajda lake, with recorded agonistic behaviour against Mallards (Anas platyrhynchos). Further spread of the Egyptian Goose, considered an invasive species in the EU, is envisaged also in Slovakia. Possible negative influence of the species on autochthonous avifauna is discussed.
\end{abstract}

Key words: Egyptian Goose, invasive alien species, distribution, Slovakia

Prirodzeným areálom rozšírenia húsky štíhlej je Afrika, južne od Sahary (Brown et al. 1982). Osídl'uje aj údolie rieky Níl až po Egypt, od čoho je odvodený aj jej anglický názov (Egyptian Goose). Jej populáciu tvorí viac ako 500000 jedincov (Banks et al. 2008). V 17. storočí bola introdukovaná na Britské ostrovy. V kontinentálnej časti Európy sa vo vol'nej prírode začala húska štíhla objavovat' koncom 19. storočia najskôr v prímorských štátoch, vo Francúzsku (r. 1800), v Nemecku (r. 1866), Belgicku (r. 1870), Pol'sku (r. 1877), odkial' sa postupne začala šírit' do južnejších oblastí (Kampe-Persson 2010).V strednej Európe sa začali jedince vo vol'nej prírode vyskytovat' až v druhej polovici 20. storočia a hniezdiace páry až v posledných desat'ročiach 20 . storočia a začiatkom 21. storočia.

Húska štíhla (Alopochen aegyptiaca, Linnaeus 1766) je v Európe považovaná za nepôvodný invázny druh, ktorého populácia tu dosahuje desiatky tisíc párov; len v Holandsku, kde jej populácia narastá najvýraznejšie, žilo po r. 2010 už vyše 50000 jedincov (Lensink 2010, Gyimesi \& Lensink 2010). V súčasnosti sa vyskytujú populácie vzniknuté z jedincov uniknutých zo zajatia vo Vel'kej Británii, v Holandsku, Belgicku, Francúzsku, Nemecku, Dánsku (Kampe-Persson 2010) a druh bol zistený aj v Českej republike (v roku 1979; Schröpfer et al. 2011), vyskytol sa aj v Rakúsku, Mad'arsku a Pol'sku. V Pol'sku je evidované prvé hniez- 
denie od r. 2007, v Českej republike bolo prvé dokázané hniezdenie v r. 2008 (Bauer-Woog 2008, Kampe-Persson 2010).

Druh preferuje biotopy s otvorenou vodnou plochou, nízkym trávnym porastom s výskytom potenciálne vhodných miest na zahniezdenie. Hniezdo je situované na zemi, ale aj v dutinách starých stromov, ale bolo nájdené aj na rôznych stavbách či zrúcaninách v blízkosti vôd. Hniezdo si stavia z trstiny a stebiel rôznych rastlín (Kalivodová \& Kalivoda 2014).

$\mathrm{Na}$ Slovensku bola húska štíhla po prvýkrát zaznamenaná v máji a začiatkom júna 1993 (1 ex.) na Hrušovskej zdrži pri Hamuliakove (Kalivodová \& Darolová 1998; Nevřelová \& Becková 2015; Tab. 1). Existujúci filmový doklad nebol posudzovaný faunistickou komisiou. Ďalší výskyt pochádza z vodnej nádrže Hričov (Ferulík in Karaska 1998), kde bol pozorovaný 1 ex. 5. 6. a 18. 6. 1996. Pozorovanie bolo akceptované Faunistickou komisiou Slovenskej ornitologickej spoločnosti/BirdLife Slovensko s tým, že išlo s najväčšou pravdepodobnost'ou o jedinca uleteného zo zajatia resp. o jedinca z polodivých populácií západoeurópskeho pôvodu (Danko \& Karaska 2002). Šrank (2008) zaradil spočiatku húsku štíhlu na základe jej prvých výskytov na Slovensku do kategórie E, kde spadajú taxóny vyskytujúce sa na území Slovenskej republiky, pričom s najväčšou pravdepodobnost'ou alebo s určitost'ou možno vylúčit' ich prirodzený pôvod (patria sem predovšetkým úniky zo zajatia); tieto taxóny sa nepočítajú do avifauny Slovenska. Pod vplyvom d'alších pribúdajúcich výskytových údajov však neskôr bola húska štíhla preradená do kategórie C (Kvetko \& FK SOS/BirdLife Slovensko 2013), kde patria introdukované taxóny, ktoré na území Slovenskej republiky vytvárajú samostatne sa udržiavajúce hniezdne populácie, alebo k nám zaletujú z takýchto populácií v zahraničí. Od r. 2007 boli už zist'o-

Tab. 1 . Prvé zaznamenané výskyty a prípady hniezdenia húsky štíhlej (Alopochen aegyptiaca) na Slovensku. Hniezdenie je označené hviezdičkou.

Table 1. First recorded occurrences and breeding cases of the Egyptian Goose (Alopochen aegyptiaca) in Slovakia. Breeding is denoted with the asterisk.

\begin{tabular}{|c|c|c|c|c|}
\hline Dátum / Date & Lokalita / Locality & $\begin{array}{l}\text { Súradnice / } \\
\text { Coordinates }\end{array}$ & $\begin{array}{l}\text { Pozorovatel', zdroj / } \\
\text { Observer, source }\end{array}$ & Poznámky / Notes \\
\hline 1993, jún / June & $\begin{array}{l}\text { Hrušovská zdrž } \\
\text { (Hamuliakovo) }\end{array}$ & $\begin{array}{l}48^{\circ} 02^{\prime} 22^{\prime \prime} \mathrm{N}, \\
17^{\circ} 14^{\prime} 04^{\prime \prime} \mathrm{E}\end{array}$ & $\begin{array}{l}\text { Kalivodová \& Darolová } \\
\text { (1998) }\end{array}$ & $1 \mathrm{ex} . /$ ind. \\
\hline 1996, jún / June & Hričov, vod. nádrž & $\begin{array}{l}49^{\circ} 14^{\prime} 49^{\prime \prime} \mathrm{N}, \\
18^{\circ} 41^{\prime} 43^{\prime \prime} \mathrm{E}\end{array}$ & Ferulík in Karaska (1998) & 1 ex. / ind. \\
\hline 11. 3. 2007 & Piešt’any - Ś́ňava & $\begin{array}{l}48^{\circ} 58^{\prime} 09^{\prime \prime} \mathrm{N}, \\
17^{\circ} 08^{\prime} 49^{\prime} 01^{\prime \prime} \mathrm{E}\end{array}$ & P. Kaňuščák & 1 ex. / ind. \\
\hline 27. -28.10 .2007 & $\begin{array}{l}\text { Borčice, Dubnické } \\
\text { štrkovisko }\end{array}$ & $\begin{array}{l}48^{\circ} 58^{\prime} 15.02^{\prime \prime} \mathrm{N}, \\
18^{\circ} 08^{\prime} 55.01^{\prime \prime} \mathrm{E}\end{array}$ & Š. Benko & $1 \mathrm{ex} . /$ ind. \\
\hline 7. 4. 2009 & $\begin{array}{l}\text { Vysoká pri Morave, } \\
\text { Devínske jazero }\end{array}$ & $\begin{array}{l}48^{\circ} 18^{\prime} 13^{\prime \prime} \mathrm{N} \\
16^{\circ} 54^{\prime} 56^{\prime \prime} \mathrm{E}\end{array}$ & J. Svetlík, R. Jureček & 4 ex. / ind. \\
\hline 27. 5. 2010 & Milhostov (okr. Trebišov) & $\begin{array}{l}48^{\circ} 40^{\prime} 17^{\prime \prime} \mathrm{N} \\
21^{\circ} 43^{\prime} 10^{\prime \prime} \mathrm{E}\end{array}$ & $\begin{array}{l}\text { P. Chrašč, } \\
\text { S. Pačenovský, M. Repel }\end{array}$ & 2 ex. / ind. \\
\hline 18. 4. 2011 & NPR Senianske rybníky & $\begin{array}{l}48^{\circ} 41^{\prime} 48^{\prime \prime} \mathrm{N}, \\
22^{\circ} 04^{\prime} 28^{\prime \prime} \mathrm{E}\end{array}$ & P. Chrašč & $1 \mathrm{ex} . /$ ind. \\
\hline $\begin{array}{l}\text { 2012, jún - júl / } \\
\text { June-July }\end{array}$ & Drahovce + Piešt'any & $\begin{array}{l}48^{\circ} 30^{\prime} 46^{\prime \prime} \mathrm{N}, \\
17^{\circ} 48^{\prime} 31^{\prime \prime} \mathrm{E}\end{array}$ & $\begin{array}{l}\text { R. Kvetko, E. Kalivodová, } \\
\text { P. Kalivoda et al. }\end{array}$ & 2 ex. / ind. \\
\hline $7 / 22 / 2013$ & Gabčíkovo, vodné dielo & $\begin{array}{l}48^{\circ} 00^{\prime} 40^{\prime \prime} \mathrm{N} \\
17^{\circ} 17^{\prime} 02^{\prime \prime} \mathrm{E}\end{array}$ & R. Kvetko & $1 \mathrm{ex} . /$ ind. \\
\hline *2014, apríl / April & Piešt’any, Síňava & $\begin{array}{l}48^{\circ} 58^{\prime} 09^{\prime \prime} \mathrm{N}, \\
17^{\circ} 08^{\prime} 49^{\prime} 01^{\prime \prime} \mathrm{E}\end{array}$ & P. Kaňuščák & $\begin{array}{l}\text { pár vyviedol } 11 \text { mlád'at / } \\
\text { pair with } 11 \text { goslings }\end{array}$ \\
\hline 2015, apríl / April & $\begin{array}{l}\text { Vysoká pri Morave, } \\
\text { Devínske jazero }\end{array}$ & $\begin{array}{l}48^{\circ} 18^{\prime} 13^{\prime \prime} \mathrm{N}, \\
16^{\circ} 54^{\prime} 56^{\prime \prime} \mathrm{E}\end{array}$ & R. Jureček, J. Svetlík & 2 ex. / ind. \\
\hline *2015, september & Jakubov, štrkovisko & $\begin{array}{l}48^{\circ} 24^{\prime} 27^{\prime \prime} \mathrm{N}, \\
16^{\circ} 54^{\prime} 56^{\prime \prime} \mathrm{E}\end{array}$ & P. Fusek, R. Jureček & $\begin{array}{l}\text { pár vyviedol } 5 \text { mlád’at / } \\
\text { pair with } 5 \text { goslings }\end{array}$ \\
\hline 2016, zima / winter & Záhorie + Považie & & $\begin{array}{l}\text { M. Mišík, R. Jureček, } \\
\text { J. Svetlík }\end{array}$ & $\begin{array}{l}\text { viacej jedincov; zimovanie / } \\
\text { more indivisuals; wintering }\end{array}$ \\
\hline $\begin{array}{l}\text { 2017, apríl, máj / } \\
\text { April, May }\end{array}$ & Dubnické štrkovisko & $\begin{array}{l}48^{\circ} 58^{\prime} 15.02^{\prime \prime} \mathrm{N}, \\
18^{\circ} 08^{\prime} 55.01^{\prime \prime} \mathrm{E}\end{array}$ & & 2 ex. / ind. \\
\hline *2017 & Jakubov, štrkovisko & $\begin{array}{l}48^{\circ} 24^{\prime} 27^{\prime \prime} \mathrm{N}, \\
16^{\circ} 54^{\prime} 56^{\prime \prime} \mathrm{E}\end{array}$ & $\begin{array}{l}\text { R. Jureček, } \\
\text { T. Danišovičová }\end{array}$ & $\begin{array}{l}\text { pár s mlád'atami / } \\
\text { pair with goslings }\end{array}$ \\
\hline *2019, júl / July & Bratislava, Kuchajda & $\begin{array}{l}48^{\circ} 10^{\prime} 05^{\prime \prime} \mathrm{N} \\
17^{\circ} 08^{\prime} 53^{\prime \prime} \mathrm{E}\end{array}$ & $\begin{array}{l}\text { J. Kal'avský, S. Pačenovský, } \\
\text { J. Šchvarcová }\end{array}$ & $\begin{array}{l}\text { pár vyviedol } 6 \text { mlád’at / } \\
\text { pair with } 6 \text { goslings }\end{array}$ \\
\hline
\end{tabular}


vané a schval'ované faunistickou komisiou pri Slovenskej ornitologickej spoločnosti/BirdLife Slovensko takmer každoročne výskyty jedincov až do súčasnosti (Šrank 2008; Šrank 2009; Kvetko \& Šrank 2012; Kvetko \& FK SOS/ BirdLife Slovensko 2015, 2016, 2017, 2018), predovšetkým zo západného Slovenska (SÍňava pri Piešt'anoch, Dubnické štrkovisko, Devínske jazero, rieka Váh pri Drahovciach ned'aleko Piešt’an, na VD Gabčíkovo na Dunaji a inde). Neskôr bol zistený výskyt druhu aj v r. 2010 na východnom Slovensku, na poli pri toku Trnávky pri Milhostove (Šrank 2011), v NPR Senné rybníky v roku 2011 (Kvetko \& Šrank 2012), d’alej bola pozorovaná najčastejšie na vodnej nádrži Sín̆ava (2007), na Záhorí bola doteraz pozorovaná v r. 2009 pri Devínskom jazere na lokalite Majsterka v počte 4 jedincov (Kvetko \& FK SOS/BirdLife Slovensko 2013). Najnovšie sa eviduje výskyt húsky štíhlej aj z okolia Martina z r. 2020 (Apfelová, pers. comm).

Doteraz, v posledných rokoch, boli na Slovensku zaznamenané preukázatel'ne 4 prípady zahniezdenia $\mathrm{v}$ prírode, všetky prípady sú uvedené v Tab. 1. Prvý prípad hniezdenia bol zistený a zdokumentovaný v roku 2014 na vodnej nádrži Síňava pri Piešt’anoch, kde vyviedol hniezdiaci pár 11 mlád'at. Ďalšie hniezdenie bolo zistené v roku 2015 na Jakubovskom štrkovisku, kde pár vyviedol 5 mlád'at. Tretí prípad hniezdenia bol zistený na rovnakej lokalite v roku 2017 . V poradí štvrtý prípad zahniezdenia a prvý prípad z Bratislavy bol zistený v roku 2019 priamo v meste, na jazere Kuchajda (obr. 1). Tunajš́i hniezdiaci pár vyviedol 6 mlád'at, avšak jedno mlád'a uhynulo v priebehu júla 2019 a d'alšie mlád'a sa stratilo v marci 2020, pravdepodobne boli predované. Voči l'ud'om sa správali húsky štíhle pomerne krotko, úniková vzdialenost' bola minimálna, len niekol'ko metrov, pred l'ud'mi unikali len vel'mi neochotne a to únikom do vody, avšak odplávali iba o niekol'ko desiatok metrov d'alej a opätovne pristávali na brehu. Hniezdenie bolo monitorované zamestnancami Štátnej ochrany prírody Slovenskej republiky. Hniezdiaci pár húsky štíhlej sa vyznačoval vel'mi agresív-

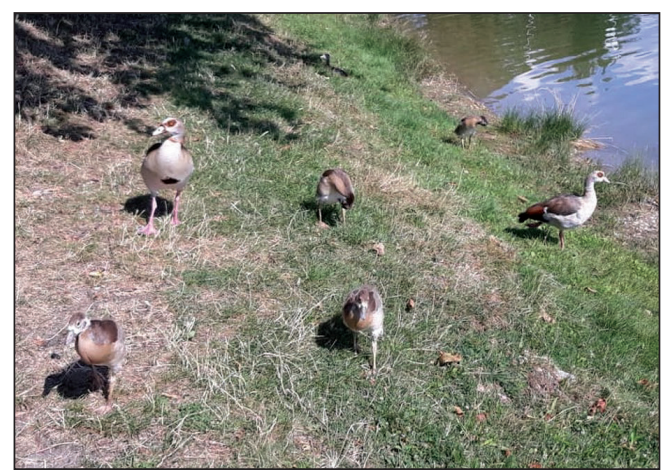

Obr. 1. Húska štíhla (Alopochen aegyptiaca), samec s mlád'atami, Bratislava, jazero Kuchajda, august 2019. Foto: S. Pačenovský.

Fig. 1. Egyptian Goose (Alopochen aegyptiaca), male with goslings, Bratislava, Kuchajda lake, August 2019. Photo by S. Pačenovský.

nym správaním voči inému vodnému vtáctvu, predovšetkým voči kačiciam divým (Anas platyrhynchos) najmä v hniezdnom období ale aj mimo neho; agresivita sa prejavovala tak, že húsky usmrtili inkubujúcu samicu kačice divej (neustálym napádaním kačice zobákom) a vytlačili všetky kačice divé (asi 60 jedincov) postupne z celej vodnej plochy jazera Kuchajda. Pre časté, s týmto spojené st’ažnosti miestnych obyvatel'ov aj samosprávy boli koncom zimy 2019/2020 niektoré jedince odchytené. Postupne bola odchytená samica $\mathrm{z}$ hniezdiaceho páru, neskôr aj 4 odrastené mlád'atá. Odchyt prebehol na ned'alekom Štrkoveckom jazere, kam sa jedince v priebehu zimy 2019/2020 premiestnili. Jedince sú umiestnené trvale v zajatí, neuvažuje sa s ich opätovným vypustením do prírody, vzhl'adom k inváznej povahe tohto druhu zúbkozobca, jeho agresivite a súvisujúcimi ohrozeniami pre iné, vol'ne žijúce druhy vodných vtákov. Dospelý samec z páru z jazera Kuchajda doteraz odchytený nebol, avšak jeho výskyt z lokality už dlhší čas nebol hlásený a tento jedinec pravdepodobne túto lokalitu opustil. Celkove do októbra 2019 bolo evidovaných v zozname vzácnych ornitologických pozorovaní podliehajúcich hláseniu Faunistickej komisii 59 záznamov (Aves Symfony 2019) a v databáze Birding Slovakia 103 záznamov húsky štíhlej (Birding Slovakia 2019). 
Je predpoklad, že sa vel'kost' populácie ako aj areál rozšírenia húsky štíhlej bude aj v d’alších rokoch rozširovat' a tým jej potenciálny negatívny vplyv narastat' či už v podobe kompetície s inými zúbkozobcami, či s inými vodnými vtákmi, prípadne hrozí aj riziko hybridizácie s inými, príbuznými druhmi (Banks et al. 2008).

$\mathrm{Na}$ húsku štíhlu sa vzt'ahuje ,Nariadenie Európskeho parlamentu a Rady (EÚ) č. $1143 / 2014$ z 22. októbra 2014 o prevencii a manažmente introdukcie a šírenia inváznych nepôvodných druhov, vykonávacie nariadenie Komisie (EÚ) 2016/145“ zo 4. februára 2016, ktorým sa prijíma zoznam inváznych nepôvodných druhov vzbudzujúcich obavy Európskej únie a ktoré sú implementované do národnej legislatívy a to zákonom č. 150/2019 Z. z., o prevencii a manažmente introdukcie a šírenia inváznych nepôvodných druhov a o zmene a doplnení niektorých zákonov. Podl'a vykonávacej vyhlášky Ministerstva životného prostredia Slovenskej republiky č. 450/2019 Z. z., ktorou sa ustanovujú spôsoby a podmienky odstraňovania inváznych nepôvodných druhov, je možné predmetné jedince invázneho druhu individuálne odchytit' alebo ulovit', pričom pri odchyte, usmrtení a nakladaní s jedincami je potrebné postupovat' $\mathrm{v}$ súlade so zákonom č. 274/2009 Z. z. o pol'ovníctve a o zmene a doplnení niektorých zákonov v znení neskorších predpisov a vyhlášky Ministerstva pôdohospodárstva Slovenskej republiky č. 344/2009 Z. z., ktorou sa vykonáva zákon o pol’ovníctve v znení neskorších predpisov.

Ohrozenie v podobe hybridizácie je zaznamenané s hrivnatkou vzpriamenou (Neochen jubata), v zajatí a vo vol'nej prírode boli pozorované hybridy s kačicou divou (Anas platyrhynchos), kazarkou hrdzavou (Tadorna ferruginea) a berniklou vel'kou (Branta canadensis) ako aj s domácimi husami (Banks et al. 2008) a domácimi kačicami (Callaghan \& Brooks 2016). Hybridizácia s pôvodnými druhmi môže ohrozit' ich prežitie (Banks et al. 2008). Vplyv na biodiverzitu je výrazný v rámci podobných topických a trofických nárokov s kačicou divou (Anas platyrhynchos) a lyskou čiernou (Fulica atra). Boli zaznamenané aj ohrozenia v podobe konkurencie o hniezdiská v hniezdnom období a to s plamienkou driemavou (Tyto alba), dokonca aj s dennými dravcami, ako napr. hajou tmavou či červenou-Milvus migrans, M. milvus (Gyimesi \& Lensink 2010).

Bratislavský hniezdny pár sa správal agresívne voči iným vtákom, predovšetkým voči kačiciam divým. Agresívne správanie sa prejavovalo tým, že obidva dospelce opakovane útočili na kačice divé, inkubujúcu samicu kačice divej usmrtili priamo na hniezde. Podobné prípady agresívneho správania, prejavujúce sa rozličným spôsobom: agresívnou ochranou svojho teritória, napádaním či zabíjaním iných vtákov, elimináciou či znížením počtu mlád'at iných druhov vtákov hniezdiacich v okolí, prípadne snahou obsadit' hniezdo iného vtáčieho druhu sú známe aj z iných krajín, napr. z Holandska, kde bolo napríklad popísané ako húska štíhla utopila 4 mlád'atá húsky pestrej (Wymenga 1999), z Belgicka, ale aj z Afriky, odkial' boli popísané agresívne strety húsky štíhlej s viacerými druhmi dravcov a vodných vtákov, či z USA, kde sa vyskytuje tiež ako invázny druh (Van Ee 1963, Gyimesi \& Lensink 2010, Koeslag 2012, Martins 2012, Callaghan \& Brooks 2016, Thompson et al. 2019). Z literatúry je teda agresívna povaha húsky štíhlej známa, aj ked' individuálne rozdiely sú možné a nie všetky hniezdiace páry sa musia správat' rovnako ako bratislavský pár. I napriek tomu vzbudzuje nesporné šírenie a zvyšovanie početnosti húsky štíhlej na Slovensku isté obavy ohl'adom možného negatívneho dopadu tohto javu na iné, autochtónne druhy vodných vtákov.

\section{Literatúra}

Aves Symfony 2019: Alopochen aegyptiaca. - http://aves. vtaky.sk/index/ Navštívené 31. 10. 2019.

Banks A. N., Wright L. J., Maclean I. M. D., Hann C. \& Rehfisch M. M. 2008: Review of the status of introduced non-native waterbird species in the area of the African-Eurasian Waterbird Agreement - Update British Trust for Ornithology, Norfolk. 
Bauer H. G. \& Woog F. 2008: Nichtheimische Vogelarten (Neozoen) in Deutschland, Teil I: Auftreten, Bestände und Status. - Vogelwarte 46: 157-194.

Birding Slovakia 2019: Alopochen aegyptiaca. - http:// www.birding.sk/index.php?lang=sk. Navštívené 31. 10. 2019.

Brown L., Urban K. \& Newman P. 1982: Birds of Africa. Vol. I. - Academic Press, London \& New York.

Callaghan C. T., Brooks D. M. 2016: Ecology, behavior, and reproduction of invasive Egyptian Geese (Alopochen aegyptiaca) in Texas. - Bulletin of the Texas Ornithological Society 49(1-2): 37-45.

DANko Š. \& KARASKA D. 2002: Kazarka štíhla (Alopochen aegyptiaca). - P. 641. In: DANKo Š., DARolová A. \& KRIŠTín A. (eds.): Rozšírenie vtákov na Slovensku. Veda, Bratislava.

Gyimesi A. \& Lensink R. 2010: Risk analysis of the Egyptian Goose in the Netherlands. - Bureau Waardenburg, Wageningen.

Kalivodová E. \& Darolová A. 1998: Vtáky slovenského úseku Dunaja a Žitného ostrova. - Združenie pre rozvoj krajinnej ekológie Biosféra, Bratislava.

Kalıvodová E. \& KalıvodA P. 2014: Zahniezdi húska štíhla aj na Záhorí? - Záhorie 23: 13-15.

Kampe-Persson H. 2010: Occurrence of Egyptian Goose Alopochen aegyptiacus in Europe. - Goose Bulletin 10(5): 34-38.

KARASKA D. 1998: Zimné sčítavanie vodného vtáctva na Orave v rokoch 1993 - 1998. — Zborník Oravského múzea 15: 175-182.

Koeslag A. 2012: Black Sparrowhawk lost battle agains Egyptian Geese. - Ornithological observations. Vol. 3: 44-45.

Kvetкo R. 2013: 13. správa Faunistickej komisie Slovenskej ornitologickej spoločnosti/BirdLife Slovensko. - Tichodroma 25: 85-93.

Kvetko R. \& FK SOS/BirdLife Slovensko 2014: 14. správa Faunistickej komisie Slovenskej ornitologickej spoločnosti/BirdLife Slovensko. - Tichodroma 26: 97-106.

KvetKo R. \& FK SOS/BirdLife SLOVENSKo 2015: 15. správa Faunistickej komisie Slovenskej ornitologickej spoločnosti/BirdLife Slovensko. - Tichodroma 27: 128-135.

KvetKo R. \& FK SOS/BirdLife SLOvensKo 2016: 16. správa Faunistickej komisie Slovenskej ornitologickej spoločnosti/BirdLife Slovensko. - Tichodroma: 106-113.
KvetKo R. \& FK SOS/BirdLife SLOvensko 2017: 17. správa Faunistickej komisie Slovenskej ornitologickej spoločnosti/BirdLife Slovensko. - Tichodroma 29: 42-48.

KvetKo R. \& FK SOS/BirdLife SLOvensKo 2018: 18. správa Faunistickej komisie Slovenskej ornitologickej spoločnosti/BirdLife Slovensko. — Tichodroma 30: 80-87.

KvetKo R. \& Šrank V. 2012: 12. správa Faunistickej komisie Slovenskej ornitologickej spoločnosti/BirdLife Slovensko. - Tichodroma 24: 102-108.

Lensink R., van Horsen P. W. \& DE Fouw J. 2010: Faunabeheerplan zomerganzen Zuid-Holland. Hoofddocument bij zeven regioplannen. - Bureau Waardenburg bv, Culemborg.

Martins M. 2012: Possible attempt by Egyptian Geese Alopochen aegyptiaca to displace Verreaux's Eagles Aquila verreauxii from their nest. - Gabar 24: 44-47.

NevŘelová B. \& Becková M. 2015: Invázne druhy živočíchov na Slovensku - pôvod, šírenie, opatrenia. Univerzita Komenského v Bratislave, Bratislava.

VAn Ee C. A. 1963: Egyptian Goose (Alopochen aegyptiacus) occupying Hamerkop nest. — Ostrich 34: 252.

ŠranK V. 2008: 8. správa Faunistickej komisie Slovenskej ornitologickej spoločnosti/BirdLife Slovensko. - Tichodroma 20: 177-179.

ŠRANK V. 2009: 9. správa faunistickej komisie Slovenskej ornitologickej spoločnosti/BirdLife Slovensko. - Tichodroma 21: 111-119.

ŠRANK V. 2011: 11. správa faunistickej komisie Slovenskej ornitologickej spoločnosti/BirdLife Slovensko. - Tichodroma 23: 77-79.

Schröpfer L., Vermouzek Z., Š́́rek J. \& StolarczyK J. 2011: Výskyt a hnízdění husice nilské (Alopochen aegyptiacus) v České republice v letech 1979 až 2009. — Sylvia 47: 67-75.

Thompson L., Hickman C., Davies J. P., Fern F. \& DowNS T. C. 2019: A review of the use of birds' nests by Egyptian geese, including a breeding attempt in a hooded vulture nest. - African Zoology 54: 169-173.

Wymenga E. 1999: Nijlgans Alopochen aegyptiacus verdrinkt jonge Bergeenden Tadorna tadorna. - Limosa 72: 106-107. 